\title{
The Effects of Light Trance and Post-Hypnotic Suggestions Towards The University Students' Reading Comprehension Improvement
}

\author{
Zainurrahman Sehan ${ }^{1 *}$, Masdi Harun¹, Idrus Ahmad² \\ ${ }^{1}$ English Department of STKIP Kie Raha Ternate \\ ${ }^{2}$ Indonesian Department of STKIP Kie Raha Ternate
}

\begin{abstract}
Post-Hypnotic suggestion has been an intriguing topic to be discussed concerning the effects it can emerge. However, there are numerous commentaries from experts regarding the need of hypnotic trance for the suggestion to take place. Hypnotherapists, practically, believe that the deeper the trance, the higher effects a suggestion takes place and raises effects (Hunter, 2010; Gunawan, 2012). Theoretically, it has been stated that suggestions can take place even without hypnotic induction and deepening to deep trance, somnambulism. Traditional hypnotic induction techniques, one of them, utilizes visualization, imagery, and relaxation. Raz \& Saphiro (2002:6-7), then, stated that hypnosis is not identical to imagery and relaxation training, because suggestion need not entail requests for imagery and, albeit not common, hypnosis can be induced without relaxation. This has been a fascinating issue concerning the alteration of consciousness the hypnotic induction may emerge, and this is still hotly debated (see Contemporary Hypnosis, Vol.22, No.1, 2005 for detail). Nevertheless, the debates concerning the trance level and suggestion effect is beyond our field. Educators in linguistics like us prefer to see the most probable hypnosis techniques usable to help our students to learn materials. In this research, the effects of post-hypnotic suggestions given to the students induced to light trance is discussed. Davis Husband Scale is employed here. Data gathered from test, observation, and interview are described..

Keywords: Light trance, hypnotic induction, reading comprehension, post-hypnotic suggestion
\end{abstract}

\section{INTRODUCTION}

The use of hypnosis as an adjunct to teach the students in educational settings has been noted by researchers as reviewed by Dale (1972). It has been proven that hypnosis is helpful and promises immeasurable rewards. London \& Cooper (1968), in contrary, showed that hypnotic

*Correspondence: zainurrahmankalero@gmail.com

Zainurrahman Sehan; English Department of STKIP Kie Raha Ternate

Buiding C, 3rd floor; STKIP Kie Raha Ternate

Ternate Town, North Maluku, Indonesia

Postal Code: 97718

\section{Sleep and Hypnosis}

Journal homepage:

www.sleepandhypnosis.org

ISSN:1302-1192 (Print) 2458-9101 (Online) suggestion could not enhance students' ability to remember materials, or at least, has no direct correlation to the memory activation. In clinical settings, hypnosis has been used to overcome psychosomatic syndromes which are considered as barriers to subject's improvement (Erickson \& Rossi, 1979). Moreover, hypnosis was also taken in constructing a communication model namely neuro-linguistic programming which has been declared by the originators as a model of communication to help people achieving self-development (Bandler \& Grinder, 1982; Bandler, 1985).

Hypnosis, then, has been one of the intriguing issues in educational settings, although it has not been officially applied in schools and universities (Wark, 2011). Regardless 
the commentaries, pros and cons, concerning hypnosis and its application, debates addressed to the methodological aspect remain exist. For instance, the debate about the alteration of consciousness during hypnosis proposed by Kallio \& Revensuo in 2003 which has been clarified in 2005 in Contemporary Hypnosis Vol. 22, No. 1. Another debate exists between the induction techniques which was ended with the conceptualization of active-alert induction (Alarcon, Capafons, Bayot, \& Kaner, 2005; Wark, 2006) which seem comparable to traditional induction technique including progressive relaxation taught by Milton $\mathrm{H}$. Erickson, Dave Elman, etc. Beyond our field, educators like us could draw a line that hypnotic induction can be accomplished without closed-eye, relaxation, and it has no need to induce the subject to deep trance level for a suggestion to have effect. However, as can be observed in our daily activity, suggestions given in 'normal state' seems to be understood (the meaning of suggestions) but changes (the effect of suggestions) in behavior rarely take place. Lecturers and teachers continuously gave suggestions, verbal positive supports, rewards, and even punishment or at least threat to the students and only small changes occurred. It is assumed that for academic settings conventional hypnotic induction needs to be applied to put the students to, at least, light trance level, to receive post- hypnotic suggestions. As mentioned by Gunawan (2012) that 'change' only occurs in subconscious level, then at least light trance is needed for a hypnotic suggestion to have effects.

Our assumption that at least light trance is needed to give effective post-hypnotic suggestion based on review towards writings in mindset, emotion, motivation, and hypnosis. It is argued by Gunawan (2012) that hypnosis can be used to change mindset. Mindset itself has been considered as a fixed mental state which determines the responses towards phenomena and has influential effects towards students' academic achievement (Dweck, 2006; Ricci, 2013). In the other side, response towards phenomena is heavily influenced by emotion related to the phenomena. In turn, emotion towards certain phenomena is influenced by the meaning given by individual toward it (Frijda, 1988). It has been noted by Bold (2004) that motivation, essentially, is a form of emotion. It is argued that the polarity of emotion toward an object shapes the motivation whether to approach or to avoid the object. Imagery visualization is an important term in hypnosis. It is believed that visualization has impact to emotion toward an object. It is actually natural since when we think or imagine a holiday or a beach we can feel positive emotion fills our heart. However, hypnotic imagery includes the information stored in subconscious level and when the information is changed then the meaning of visualized object is also changed based on the operator's guidance (Gunawan, 2012). If the meaning is changed, then the emotion is consequently changed. In turn, the motivation is also changed. Related to this case, it is not needed to state explicitly again that learning motivation is a crucial element of learning achievement. However, increasing students' motivation is not all of this research. The researchers also employed hypnotic suggestion to maintain students' focus in reading, bringing positive emotion when reading, and decreasing students' anxiety during test after hypnosis session. These sub-objectives are integrally accomplished in to the hypnotic script used during hypnotic light trance.

\section{METHODS}

The result of this study was not intended to be generalized to the broader context. This study was accomplished to understand the effects of light trance post-hypnotic suggestions to the reading comprehension improvement of the students participated in this research. The researchers observed, interviewed, and tested the students by giving them reading text which is then followed by questions related to the text. Five students participated in this study. They were purposively selected by considering their low reading scores obtained from their lecturer. The students were also chosen based on their level of suggestibility and this study preferred to take students in medium level of suggestibility. A test of suggestibility was accomplished.

Preliminary test was given to the students to obtain the basic data of their reading comprehension. The test was designed in multiple choices (20 questions) and the material of the test was taken from the reading text written 
in 350 words long. 20 minutes were given to the students to read the text, and then they started to answer the questions which were separated from the reading text. This data, which were interpreted by using descriptive statistic, were compared to the text given after the hypnosis session. During hypnosis session, the students were suggested to (1) be relax during reading and accomplishing the test, (2) be more focused during reading, (3) be positively emotional during reading, (4) and be motivated to read for understanding the text content.

After hypnosis session, the students were required to read the next text of different topic but written in the same long. Students were given 20 minutes to read the text. Here, the researchers observed the students. This observation was done to see how the students accomplish the reading session. Field notes were taken from the observation process and the observation process continued as the reading session continued to the second test session.

After the second test session, the students were asked to share their subjective experience concerning the effects of post-hypnotic suggestion given during hypnosis session. The interview was designed as unstructured interview. These multiple data collection techniques were employed to deepen our understanding on the students' subjective experience and also improvement the students achieved.

\section{RESULT}

\section{Preliminary Test}

The data gathered from the preliminary test showed that the students' reading comprehension ability was low. It can be seen from the table below that from 20 multiple choice questions, total percentage for true answer is below $40 \%$. The amount of students' true answer was various but it is still in a low range (TA stands for true answer).

Table 1. The students' reading scores before the hypnosis session

\begin{tabular}{cc} 
Ss & \% of TA \\
\hline 1 & $35 \%$ \\
2 & $30 \%$ \\
3 & $35 \%$ \\
4 & $35 \%$ \\
5 & $25 \%$ \\
\hline$M$ & $32 \%$ \\
\hline
\end{tabular}

Data from the lecturer who was teaching the reading subject inform that these students' scores in the reading subject were also low and the data from this preliminary test confirmed it. This data was needed only to see the students' reading comprehension ability before the hypnosis session.

\section{Hypnosis Session}

During the hypnosis session, the students participated into the session voluntarily. The researchers observed that the students follow all instructions given from the suggestibility test until the termination phase. These students also never involved in any hypnosis activity before. Therefore, the researchers firstly gave general information related to hypnosis.

The researcher induced the students by using progressive relaxation and the students were induced in almost 15 minutes. The researcher, then, used staircase imagery to deepen the trance to the edge of light trance. The trance level was confirmed through David Husband Scale, where the students' experience eye catalepsy and relaxation on body parts. Giving the post-hypnotic suggestions took almost 40 minutes; agreement for each suggestion was confirmed by the students via ideomotor response. It was observed that no student denied the suggestions given. In this chance, the researchers also suggested that reading is a process of gathering information from the text and their mind is excited during the reading process. This suggestion was repeated about seven times. This suggestion was given as the "new" meaning of reading activity for them.

After giving the post-hypnotic suggestions, the researchers did the termination by using conventional terminating instruction and suggestions. It was observed that all the students were not directly commenting the session rather than showing a "flat" facial expression as if they were still in trance. About 8 minutes later, they started communicated each other about their experience during in trance. Here, the researchers wondered if some of them were in medium trance; it was noted that a student said that he could not move his entire body during the process except his right pointing finger. 


\section{Reading after Hypnosis Session (Observation and Test)}

10 minutes after the hypnosis session, the students were asked to take the second reading text. It is observed that the students were calm and their smile could be seen clearly from their face. It was also seen that they were so relaxed during the second reading session.

Two of them asked some questions politely on some words they found unfamiliar. The researchers gave short explanation about those words then the students continued to read. The students' were seemed able to sustain their focus on the text they read. They were given 20 minutes for the reading session but they have finished their reading in 14-15 minutes. The researchers distributed the question forms and they were seemed so ready when taking those forms. It was very joyful when they said "thank you, sir" when they took the form; their lecturer said that this was not familiar expression for these five students.

The score for the second reading and test can be seen in the table below:

Table 2. The students' reading scores after the hypnosis session

\begin{tabular}{cc} 
Ss & \% of TA \\
\hline 1 & $90 \%$ \\
2 & $95 \%$ \\
3 & $95 \%$ \\
4 & $85 \%$ \\
5 & $100 \%$ \\
\hline$M$ & $93 \%$ \\
\hline
\end{tabular}

We can see that albeit one of the students reaches $85 \%$ and only one student reaches $100 \%$, but the range of the students' score is above $75 \%$ (compare with the preliminary test scores). The students showed that they could read the text better than before.

\section{Students' Subjective Experiences (Data from interview)}

After looking at the students' results, the researchers invited the students and accomplished an unstructured interview. The purpose of this interview was to gather information regarding their subjective experience during the reading after hypnosis session. The researchers did not give starting questions to avoid the occurrence of leading the students. Therefore, the researchers just asked the students to tell or to share their experience during this process. The data has been reduced and some important points have been noted as follow:

\section{Eyes-text engagement}

The students said that they felt as if their eyes won't move from the text they were reading (except two students who asked some questions). They also said that the text seemed to draw their eyes (they meant their attention). Some of them were aware that their phone was ringing but it did not distract their concentration. They said, "The phone was ringing, but I didn't feel necessary to take it up. My eyes kept reading."

\section{Relaxation}

The students said that they did not feel any force when reading the text. When they were asked if they have any important appointment today, three of them said yes but it was not very urgent. Even, they did not remember if they have others appointment until it was asked. The same responses were given when they were asked about their feeling when doing the test. They said that, as if, they have had the answers. Moreover, one of them said that "I thought I have known the questions." This response showed that the students feel no mental force or anxiety when they involved in the testing session.

\section{Recalling Ability}

The students said that everything seemed to be connected clearly (they meant the questions and the text they read). When they read the question, they could easily recall the content of the text. They stated this in various sentences, but it can be paraphrased "I understood the question and I knew which parts of the text contains the answer, and I knew the answer."

\section{DISCUSSION}

The students' scores have shown that their reading comprehension improves. The difference between the scores could be considered as the gain they achieve. It has 
been known that hypnosis might not have direct effect to their reading comprehension, but the post-hypnotic suggestions given have. This result leads the researchers to recall what was implied by London \& Cooper (1968) that hypnosis does not affect students' learning result automatically, but there is "associative chain" (their terms concerning memory activation) which makes it possible to use hypnosis to improve students' learning result.

The students' experience of feeling engaged to the text was considered as the effect of the post-hypnotic suggestion for increasing their ability to focus and to maintain the focus. This should be related to the general definition of hypnosis as a state when the subjects' attention was heightened. However, the students' subjective experience showed that their heightened attention was also happened in the normal state (after hypnosis) and this could be considered as the posthypnotic suggestion effect. The anchoring concept is applicable here; the trigger was the text.

Being relaxed during learning and under examination as a post-hypnotic suggestion effect was noted by most researchers and one of them was Dale (1972). The students' subjective experience confirmed this issue.

\section{References}

Alarcon, A., Capafons, A., Bayot, A., Kaner, Y. N. (2005). Activealert hypnotic induction methods: The relationship between phenomenological experience, pleasantness and hypnotic suggestibility. International Journal of Psychology and Psychological Therapy, 5(1), 36-46.

Bandler, R. (1985). Neuro-linguistic programming: Using your brain for a change. Utah: Real People Press.

Bandler, R., \& Grinder, J. (1982). Reframing: Neuro-linguistic programming and the transformation of meaning. Utah: Real People Press.

Bold, C. (2004). Supporting learning and teaching. London: David Fulton Publisher Ltd.

Bos, S. (2002). The brain: Implications for teaching and learning. Los Angeles: Community Works Press.

Dale, R. A. (1972). Hypnosis and education. Retrieved from ERIC Database

Dweck, C. S. (2006). Mindset: The new psychology of success. Manhattan: Random House.
Emotion and motivation played important role in this occasion. The post-hypnotic suggestion to enhance their positive emotion during writing is seemed to work well here. This is in line with Bos (2002) who stated that negative feeling could resist students' learning process and in contrary positive feeling could enhance it.

The students' recalling ability increase was considered as the other side of the heightened attention during the writing process. To say that this has to do with their brain or mind dynamics is beyond our right. We don't have enough data and brain imaging devices to state this. Therefore, we considered that as the other positive side of the post-hypnotic suggestion for heightening the attention during the reading session.

However, although this study concluded that posthypnotic suggestion given when the students were in the light trance could be useful to improve students' reading comprehension this research was lack of instrument and data. Nevertheless, it was an interesting result for educators like us. As the researchers have only general readings in neuroscience and hypnosis, the researchers could not go too far beyond our field. Also, the researchers do not declare any conflict of interest in this report.

Erickson, M. H. and Rossi, E. L. (1979). Hypnotherapy: An exploratory casebook. New York: John Wiley Sons, Inc.

Frijda, N. H. (1988). The laws of emotion. American Psychological Association. 43(5), 349-358

Gunawan, A. W. (2012). Hypnotherapy: The art of subconscious restructuring. Jakarta: Gramedia Pustaka Utama

Hunter, R. (2010). The art of hypnotherapy. United Kingdom: Crown House Publishing Ltd.

Raz, A., \& Shapiro, T. (2002). Hypnosis and neuroscience: A cross talk between clinical and cognitive research. Hypnose, 3(2), 4-18.

Ricci, M. C. (2013). Mindsets in the classroom. Waco: Prufrock Press.

Wark, D. M. (2011). Traditional and alert hypnosis for education: a literature review. American Journal of Clinical Hypnosis. 54, 96 106.

Wark, D. M. (2006). Alert hypnosis: a review and case report. American Journal of Clinical Hypnosis. 48(4), 291-300. 